\title{
Characterizing Health Care Delays and Interruptions in the United States During the COVID-19 Pandemic: Internet-Based, Cross-sectional Survey Study
}

Elizabeth Lerner Papautsky ${ }^{1}$, BSc, MSc, PhD; Dylan R Rice ${ }^{2}$, BA; Hana Ghoneima ${ }^{3}$; Anna Laura W McKowen ${ }^{3}$, MA; Nicholas Anderson ${ }^{3}, \mathrm{BA}, \mathrm{MSc}$; Angie R Wootton ${ }^{4}, \mathrm{MSW}$; Cindy Veldhuis ${ }^{3}, \mathrm{PhD}$

\footnotetext{
${ }^{1}$ Department of Biomedical \& Health Information Sciences, College of Applied Health Sciences, University of Illinois at Chicago, Chicago, IL, United States

${ }^{2}$ Department of Neurology, Massachusetts General Hospital, Boston, MA, United States

${ }^{3}$ Department of Counseling \& Clinical Psychology, Teachers College, Columbia University, New York, NY, United States

${ }^{4}$ School of Social Welfare, University of California Berkeley, Berkeley, CA, United States
}

\section{Corresponding Author:}

Elizabeth Lerner Papautsky, BSc, MSc, PhD

Department of Biomedical \& Health Information Sciences

College of Applied Health Sciences

University of Illinois at Chicago

1919 W Taylor St

Chicago, IL, 60612

United States

Phone: 13129960357

Email: elp@uic.edu

\section{Abstract}

Background: The COVID-19 pandemic has broader geographic spread and potentially longer lasting effects than those of previous disasters. Necessary preventive precautions for the transmission of COVID-19 has resulted in delays for in-person health care services, especially at the outset of the pandemic.

Objective: Among a US sample, we examined the rates of delays (defined as cancellations and postponements) in health care at the outset of the pandemic and characterized the reasons for such delays.

Methods: As part of an internet-based survey that was distributed on social media in April 2020, we asked a US-based convenience sample of 2570 participants about delays in their health care resulting from the COVID-19 pandemic. Participant demographics and self-reported worries about general health and the COVID-19 pandemic were explored as potent determinants of health care delays. In addition to all delays, we focused on the following three main types of delays, which were the primary outcomes in this study: dental, preventive, and diagnostic care delays. For each outcome, we used bivariate statistical tests $(t$ tests and chi-square tests) and multiple logistic regression models to determine which factors were associated with health care delays.

Results: The top reported barrier to receiving health care was the fear of SARS-CoV-2 infection (126/374, 33.6\%). Almost half $(1227 / 2570,47.7 \%)$ of the participants reported experiencing health care delays. Among those who experienced health care delays and further clarified the type of delay they experienced $(921 / 1227,75.1 \%)$, the top three reported types of care that were affected by delays included dental $(351 / 921,38.1 \%)$, preventive $(269 / 921,29.2 \%)$, and diagnostic $(151 / 921,16.4 \%)$ care. The logistic regression models showed that age $(P<.001)$, gender identity $(P<.001)$, education $(P=.007)$, and self-reported worry about general health $(P<.001)$ were significantly associated with experiencing health care delays. Self-reported worry about general health was negatively related to experiencing delays in dental care. However, this predictor was positively associated with delays in diagnostic testing based on the logistic regression model. Additionally, age was positively associated with delays in diagnostic testing. No factors remained significant in the multiple logistic regression for delays in preventive care, and although there was trend between race and delays (people of color experienced fewer delays than White participants), it was not significant $(P=.06)$.

Conclusions: The lessons learned from the initial surge of COVID-19 cases can inform systemic mitigation strategies for potential future disruptions. This study addresses the demand side of health care delays by exploring the determinants of such delays. More research on health care delays during the pandemic is needed, including research on their short- and long-term 
impacts on patient-level outcomes such as mortality, morbidity, mental health, people's quality of life, and the experience of pain.

(J Med Internet Res 2021;23(5):e25446) doi: 10.2196/25446

\section{KEYWORDS}

COVID-19; health care delays; internet survey; preventive care; delay; interruption; lockdown; precaution; prevention; social media; survey

\section{Introduction}

Times of disaster have often been characterized by a lack of access to health care, treatment delays or interruptions, and medication shortages [1-4]. The COVID-19 pandemic has broader geographic spread and potentially longer lasting effects than those of previous disasters. Further, the care of patients with COVID-19 has overburdened health care systems, and seeking health care may put patients at risk of exposure to SARS-CoV-2. Implementing necessary infection prevention precautions for the transmission of SARS-CoV-2 (the virus that causes COVID-19) and allocating resources (eg, personal protective equipment, beds, and personnel) in anticipation of or in response to a surge of COVID-19 cases has resulted in delays in and cancellations of in-person health care services, especially at the outset of the pandemic. These delays may affect a large proportion of patients. For example, in a recent study about health care delays at the outset of the pandemic among breast cancer survivors (April 2 to April 27, 2020; $N=609$ ), 44\% of participants reported breast cancer treatment delays [5]. The consequences can be significant for individuals with conditions that require timely intervention, such as cancer, other chronic health conditions, and mental health concerns. The deleterious effects of postponing preventive, diagnostic, and dental health care may include the delayed or missed diagnosis of life-threatening illnesses such as cancer, the exacerbation of illnesses, and even death. Given the potential implications for the morbidity and mortality of delaying or not accessing health care, it is important to document delays and interruptions in health care access during the COVID-19 pandemic to inform appropriate intervention efforts.

Of great interest and concern are delays in preventive and diagnostic care, particularly delays in such care for older adults. Before the pandemic, approximately $50 \%$ of all adults received the recommended preventive care in the United States [6-8]. Thus, people with pre-existing and emerging conditions may not be receiving needed health care management-a problem that was not introduced but rather amplified by the pandemic. Further, as preventive and diagnostic care are the first line of defense for diagnosing life-threatening illness, delays and interruptions may result in higher mortality and morbidity. This is of particular concern for older adults, given that age is the main risk factor for cardiovascular disease, cancer, and neurodegenerative conditions [9], and such conditions may be exacerbated by stress and isolation during the pandemic. Emerging studies on delayed and interrupted care have focused on specialties such as head and neck malignancies [10], urologic surgeries [11], and heart failure [12]. Ding and colleagues [13] documented the potentially fatal consequences of care delays for COVID-19-negative patients requiring in-person medical care for timely diagnosis. They described five pediatric patient cases with poor clinical outcomes resulting from delays in cancer diagnosis. These poor outcomes unfortunately occurred despite the fact that several patients interacted with primary care providers through telehealth visits prior to presenting at the hospital. Due to the effects of the COVID-19 pandemic on people's access to health care, the oncology community anticipates an uptick in the number of cancer diagnoses and diagnoses at higher cancer stages and an increase in cancer mortality rates overall [14]—a devastating and sobering concern. Research with a focus on older adults is needed to characterize the near- and long-term impacts of delayed and interrupted care on health and inform effective and person-centered solutions to protect severely ill but treatable patients.

To address a gap in our understanding of the effects of the pandemic on health care access, we examined the rates of delays in health care among a US convenience sample at the outset of the pandemic, with a specific focus on preventive care. Our study reflects Americans' experiences with the demand for health care. We also characterized the reasons for such delays. As we navigate the pandemic and the potential resurgences of infections, our findings can inform systems-level strategies for future public health emergencies to mitigate delays, improve effective communications for addressing uncertainty, and promote mental health interventions.

\section{Methods}

\section{Study Design}

In April 5, 2020, we launched an internet-based survey study examining the impact of the COVID-19 pandemic on mental health and well-being. Participants were invited to take part in a study that focused on "how the pandemic is affecting you" through social media (ie, Twitter and Facebook), listservs, social networks, websites (eg, Buzzfeed), and the research match website at Columbia University. Information about this study was included in the beginning of the survey; participants indicated consent by proceeding to the survey. The survey comprised multiple validated instruments as well as items that were developed to help us understand experiences that were specific to the COVID-19 pandemic. The mean completion time for the full survey was approximately 35 minutes. As this study was not funded, participants were not offered compensation. At the culmination of the survey, participants were provided with a list of resources (eg, crisis hotlines) in case they experienced distress. Participants were also asked to provide their email addresses if they consented to being recontacted for future follow-ups. Participants who provided their email addresses were surveyed again between April 26 and May 5, 
2020. All study procedures were reviewed and approved by the Columbia University Institutional Review Board.

\section{Measures}

Participants were asked about any interruptions they experienced to their health care in the following item, which was developed specifically for this study: "Have you experienced any delays or interruptions in your healthcare (e.g. cancelled or delayed appointments, tests, procedures) during the coronavirus outbreak?" Response options for this item were dichotomous ("yes" or "no"), and participants who responded affirmatively were asked to elaborate with an open-ended, text-based answer. Responses ranged from no delayed care to multiple types of delayed care. Some participants included more detailed responses.

\section{Data Coding and Analysis}

To characterize and code the types of delays, we used Microsoft Excel. Three researchers (ELP, DR, and HG) coded participants' responses to the open-ended item about the types of health care delays and interruptions they experienced $[15,16]$. The coding process was as follows. First, one researcher (DR) reviewed a set of 25 randomly selected responses and developed a draft codebook, which primarily focused on the types of care affected. Second, the three researchers collaboratively reviewed the codebook draft and planned the logistics of the coding process. Each researcher coded the same 50 responses, identified coding uncertainties, and noted potential codebook edits. To establish interrater reliability, the three researchers discussed coding discrepancies until they were resolved with $100 \%$ agreement among all three researchers. The codebook was edited to clarify codes, add additional codes, and remove codes. Third, each researcher coded a third of the remaining responses. Any uncertainties were resolved by communication and discussion with the other two researchers. Finally, upon completion, researchers debriefed to further refine the codebook (eg, adding a dermatology code based on its frequency of appearance in the data set). All codes $(n=2776)$ were integrated into a single spreadsheet.

\section{Statistical Analysis}

Basic descriptive statistics were used to describe the research sample. We conducted two sets of inferential procedures to determine which factors were associated with self-reported health care delays, with a focus on three outcome variables. First, we examined the determinants of experiencing any health care delays due to the pandemic (dichotomous variable; "yes" or "no"). Among those who experienced delays, we were particularly interested in the following three types of delays: dental, preventive, and diagnostic care delays. For each dependent variable, bivariate analyses were conducted to describe the associations of the outcomes with demographic characteristics or self-reported levels of worry about their general health and COVID-19. Independent samples $t$ tests were used for continuous independent variables, whereas chi-square tests were used for categorical variables. All independent variables were then entered into a multiple logistic regression model; R (The R Foundation) [17] was used for the statistical inference procedures.

\section{Results}

The analytic sample for this study included 2570 participants (accounting for missing data in the delays question) from across all US states who completed the survey between April 5, 2020, and May 5, 2020. Participants' ages ranged from 18 to 84 years (mean 37.3 years, SD 12.6 years). The majority of participants were non-Hispanic White (2464/2570, 95.9\%), were cisgender (ie, gender identity is consistent with the sex assigned at birth) women $(2456 / 2570,95.6 \%)$, were heterosexual $(1680 / 2570$, $65.4 \%)$, and had at least a Bachelor's degree $(1259 / 2570,50 \%)$. Table 1 shows a summary of demographics. 
Table 1. Sample characteristics ( $\mathrm{N}=2570)$.

\begin{tabular}{|c|c|}
\hline Variable & Value \\
\hline \multicolumn{2}{|l|}{ Numeric variables, mean (SD) } \\
\hline Age (years) & $37.31(12.63)$ \\
\hline Distance to hospital (miles) & $2.30(0.95)$ \\
\hline Health-related worry (scale of 0-100) & $52.27(26.71)$ \\
\hline COVID-19-related worry (scale of 0-100) & $74.93(20.54)$ \\
\hline \multicolumn{2}{|l|}{ Categorical variables, $\mathbf{n}(\%)$} \\
\hline \multicolumn{2}{|l|}{ Gender } \\
\hline Cisgender women & $2456(95.6)$ \\
\hline Cisgender men & $324(12.6)$ \\
\hline Transgender or nonbinary individuals & $118(5.6)$ \\
\hline \multicolumn{2}{|l|}{ Sexual identity } \\
\hline Heterosexual & $1680(65.4)$ \\
\hline Sexual minority & $1202(46.8)$ \\
\hline \multicolumn{2}{|l|}{ Race and ethnicity } \\
\hline White & $2464(95.9)$ \\
\hline Black & 48 (1.9) \\
\hline Latina, Latino, Latinx, or Hispanic & $174(6.8)$ \\
\hline American Indian or Alaska Native & $0(0)$ \\
\hline Asian or Pacific Islander & $199(7.7)$ \\
\hline Biracial & $7(<1)$ \\
\hline \multicolumn{2}{|l|}{ Education } \\
\hline High school or less & $57(2.2)$ \\
\hline Less than a Bachelor's degree & $419(16.3)$ \\
\hline Bachelor's degree & $783(30.5)$ \\
\hline Enrolled in graduate school & $287(11.2)$ \\
\hline Graduate or professional school & $894(34.8)$ \\
\hline Doctorate degree (eg, MD, PhD, DrPH) & $449(17.5)$ \\
\hline
\end{tabular}

Almost half $(1227 / 2570,47.8 \%)$ of all participants reported experiencing delays or interruptions in their health care. Of these, $8.3 \%(102 / 1227)$ reported switching their care to telemedicine, and $12.6 \%(154 / 1227)$ reported experiencing health care access issues (eg, barriers associated with insurance coverage). Most participants (921/1227, 75.1\%) who experienced delays specified the types of affected care. Some individuals solely responded with phrases such as "doctor's appointment," which resulted in no associated code due to the lack of the specificity of the response. Among those that specified the type of care, the three most commonly reported types of care affected included dental (351/921, 38.1\%), preventive (269/921, 29.2\%), and diagnostics (151/921, 16.4\%) care (Figure 1). Emergency care was the least commonly reported type of care affected $(12 / 921,1.3 \%)$ among this sample, followed by vaccinations $(14 / 921,1.5 \%)$ and cancer care (14/921, 1.5\%). Further, 10.2\% (94/921) of the participants who responded to this item reported disruptions to the health care of others (eg, child, spouse, and parent; not included in Figure $1)$. 
Figure 1. Types of health care impacted by the COVID-19 pandemic (n=921). Proportions do not sum to $100 \%$ because participants may have listed $>1$ type of care. OGBYN: obstetrics and gynecology.

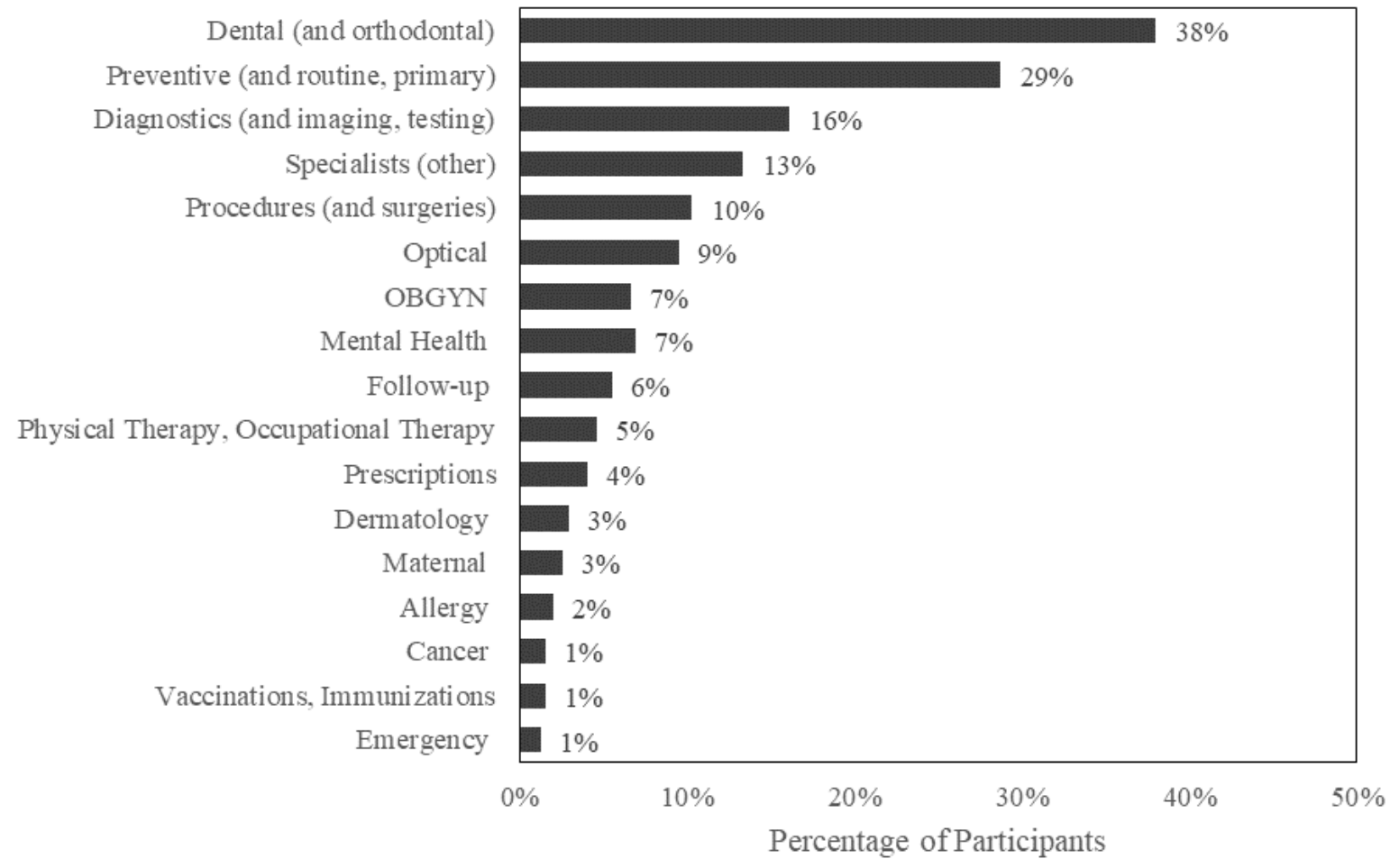

In Table 2, we present the reported barriers to receiving health care services, which were based on follow-up questions that were sent to individuals who indicated an interest in participating in follow-up questionnaires. The top 3 barriers to care-each reported by about one-third of participants - included a fear of
SARS-CoV-2 infection (126/374, 33.7\%), provider discouragement $(122 / 374,32.6 \%)$, and the feeling that their health care concerns were not as important as others' concerns $(118 / 374,31.6 \%)$.

Table 2. Barriers to receiving health care during the COVID-19 pandemic $(n=1025)$. Responses to the following question are presented: "Since the start of the coronavirus pandemic, have you needed to get healthcare but haven't gotten it? Why?"

\begin{tabular}{ll}
\hline Responses & Value, $\mathrm{n}(\%)^{\mathrm{a}}$ \\
\hline No & $651(63.5)$ \\
Yes & $374(36.5)$ \\
I was afraid of getting infected & $126(33.7)$ \\
My health care provider discouraged me from coming in & $122(32.6)$ \\
I felt like my concern/need wasn't as important as other people's & $118(31.6)$ \\
My health care provider is unavailable & $108(28.9)$ \\
I felt like my symptoms weren't severe enough & $89(23.8)$ \\
I have no health insurance & $15(4)$ \\
I cannot afford my copay or deductible & $14(3.7)$ \\
Other & $60(16)$ \\
\hline
\end{tabular}

${ }^{\mathrm{a}}$ Proportions do not sum to $100 \%$ because participants may have listed $>1$ reason.

Determinants of Patient-Reported Health Care Delays

Table 3 shows the associations between the dependent variable "any health care delays" and independent variables as a series of separate bivariate tests. Several demographic factors were associated with reporting any health care delays resulting from the pandemic. On average, older age, cisgender women, White individuals, higher levels of education, higher levels of self-reported worries about general health, and higher levels of self-reported worries about COVID-19 were all associated with experiencing health care delays. We then entered all independent variables, regardless of their significance at the bivariate level, into a multiple logistic regression model. The results from the logistic regression models indicated that age $(P<.001)$, gender 
identity $(P<.001)$, race $(P=.005)$, education $(P=.007)$, and the degree of worry about COVID-19 $(P<.001)$ and general health $(P<.001)$ were all significantly associated with experiencing health care delays due to the pandemic. The largest effect was observed for gender; the odds of patient-reported health care delays for cisgender men were 0.60 (95\% CI 0.46-0.78) times that of cisgender women.

Table 3. Bivariate analyses ${ }^{\mathrm{a}}$ of the reasons for experiencing health care delays resulting from the COVID-19 pandemic (N=2570).

\begin{tabular}{|c|c|c|c|}
\hline Independent variables & Yes & No & $P$ value \\
\hline Age (years), mean (SD) & $38.9(13.1)$ & $36.0(12.1)$ & $<.001$ \\
\hline \multicolumn{4}{|l|}{ Gender identity, \% } \\
\hline Cisgender women & 87.2 & 83.8 & $<.001$ \\
\hline Cisgender men & 8.3 & 13.4 & $-^{c}$ \\
\hline Transgender or nonbinary individuals & 4.6 & 3.8 & - \\
\hline \multicolumn{4}{|l|}{ Race, $\%^{b}$} \\
\hline White & 87.8 & 83.9 & .005 \\
\hline People of color & 12.2 & 16.1 & - \\
\hline \multicolumn{4}{|l|}{ Sexual identity, \%b } \\
\hline Heterosexual & 60 & 57.6 & .22 \\
\hline Sexual minority & 40 & 42.4 & - \\
\hline \multicolumn{4}{|l|}{ Education, $\%^{b}$} \\
\hline Less than a Bachelor's degree & 17 & 14.6 & .007 \\
\hline Bachelor's degree or some graduate school & 38.9 & 35.3 & - \\
\hline Graduate or doctorate degree & 44.1 & 50.2 & - \\
\hline Distance to nearest hospital (miles), mean (SD) & $2.3(1.0)$ & $2.3(0.9)$ & .15 \\
\hline Worry about general health (scale of $0-100$ ), mean (SD) & $54.5(27.0)$ & $50.1(26.2)$ & $<.001$ \\
\hline Worry about COVID-19 (scale of 0-100), mean (SD) & $76.3(20.4)$ & $73.6(20.6)$ & $<.001$ \\
\hline
\end{tabular}

${ }^{a}$ Bivariate tests are used to determine whether each independent variable is related to each dependent variable. Continuous independent variables are used in an independent samples $t$ test to identify a significant association, while categorical independent variables are used in a chi-square test of association.

${ }^{\mathrm{b}}$ Percentages are based on column totals.

${ }^{\mathrm{c}}$ Not available.

We also examined delays in specific types of health care-dental, preventive, and diagnostics care. Both the bivariate tests (Table 4) and the multiple logistic regression model (Table 5) showed that the only significant independent variable that was associated with dental delays was self-reported worries about general health. Increased levels of worry were associated with fewer delays in dental care $(P=.002)$. Our bivariate analyses identified two factors that were associated with experiencing delays in diagnostics (Table 4) —age and self-reported worry about general health. In the multiple logistic regression model, both factors remained significant at the .05 level of confidence. Age had a larger effect on experiencing delays in diagnostics. Every 10-year increase in age increased the odds of experiencing delays in diagnostics by a multiple of 1.36 . The bivariate tests of association for delays in preventive care showed that age $(P=.03)$ and race and ethnicity $(P=.02)$ were significant. Neither of these factors remained significant in the multiple logistic regression model, and although there was trend between race and delays (people of color experienced fewer delays than White participants), it was not significant $(P=.06)$. 
Table 4. Bivariate analyses of the reasons for experiencing health care delays resulting from the COVID-19 pandemic among those who reported experiencing any health care delays $(\mathrm{N}=921)$.

\begin{tabular}{|c|c|c|c|c|c|c|c|c|c|}
\hline \multirow[t]{3}{*}{ Independent variables } & \multicolumn{9}{|c|}{ Dependent variables } \\
\hline & \multicolumn{3}{|c|}{ Delays in dental care } & \multicolumn{3}{|c|}{ Delays in diagnostics } & \multicolumn{3}{|c|}{ Delays in preventive care } \\
\hline & Yes & No & $\begin{array}{l}P \\
\text { value }\end{array}$ & Yes & No & $\begin{array}{l}P \\
\text { value }\end{array}$ & Yes & No & $\begin{array}{l}P \\
\text { value }\end{array}$ \\
\hline Age (years), mean (SD) & $39.3(13.3)$ & $39.3(13.3)$ & .50 & $43.6(13.3)$ & $38.8(13.1)$ & $<.001$ & $41.1(13.3)$ & $38.9(13.0)$ & .03 \\
\hline Gender, \% & & & .94 & & & .36 & & & .24 \\
\hline Cisgender women & 86.6 & 87 & & 88.1 & 86.6 & & 89.2 & 85.9 & \\
\hline Cisgender men & 8.8 & 8.3 & & 6 & 9 & & 7.8 & 8.7 & \\
\hline $\begin{array}{l}\text { Transgender or nonbinary individu- } \\
\text { als }\end{array}$ & 4.6 & 4.7 & & 6 & 4.4 & & 3 & 5.4 & \\
\hline Race, \% & & & .99 & & & .38 & & & .02 \\
\hline White & 88.9 & 89.1 & & 86.7 & 89.5 & & 92.9 & 87.4 & \\
\hline People of color & 11.1 & 10.9 & & 13.3 & 10.5 & & 7.1 & 12.6 & \\
\hline Sexual identity, \% & & & .22 & & & .99 & & & .07 \\
\hline Heterosexual & 61.1 & 56.9 & & 58.3 & 58.5 & & 63.2 & 56.5 & \\
\hline Sexual minority & 38.9 & 43.1 & & 41.7 & 41.5 & & 36.8 & 43.5 & \\
\hline Education, \% & & & .89 & & & .60 & & & .09 \\
\hline Less than a Bachelor's degree & 13.7 & 14.7 & & 14.6 & 14.3 & & 11.9 & 15.3 & \\
\hline $\begin{array}{l}\text { Bachelor's degree or some graduate } \\
\text { school }\end{array}$ & 35.9 & 34.9 & & 31.8 & 36 & & 32.3 & 36.5 & \\
\hline Graduate or doctorate degree & 50.4 & 50.4 & & 53.6 & 49.7 & & 55.8 & 48.2 & \\
\hline $\begin{array}{l}\text { Distance miles to nearest hospital } \\
\text { (miles), mean (SD) }\end{array}$ & $2.3(0.9)$ & $2.4(1.0)$ & .25 & $2.3(1.0)$ & $2.3(1.0)$ & .87 & $2.3(0.9)$ & $2.3(1.0)$ & .73 \\
\hline $\begin{array}{l}\text { Worry about general health (scale of } 0 \text { - } \\
100 \text { ), mean (SD) }\end{array}$ & $50.5(27.2)$ & $56.1(26.4)$ & .002 & $60.2(26.0)$ & $52.8(26.8)$ & .001 & $54.3(25.2)$ & $53.8(27.5)$ & .81 \\
\hline $\begin{array}{l}\text { Worry about COVID (scale of 0-100), } \\
\text { mean (SD) }\end{array}$ & $75.8(20.6)$ & $77.1(20.3)$ & .38 & $79.0(19.3)$ & $76.1(20.6)$ & .11 & $77.2(19.2)$ & $76.3(20.9)$ & .54 \\
\hline
\end{tabular}


Table 5. Multiple logistic regression of reasons for experiencing health care delays resulting from the COVID-19 pandemic.

\begin{tabular}{|c|c|c|c|c|c|c|c|c|}
\hline \multirow[t]{3}{*}{ Independent variables ${ }^{\mathrm{a}}$} & \multicolumn{8}{|c|}{ Dependent variables ${ }^{\mathrm{b}}$} \\
\hline & \multicolumn{2}{|c|}{ Any delays } & \multicolumn{2}{|c|}{ Delays in dental care } & \multicolumn{2}{|c|}{ Delays in diagnostics } & \multicolumn{2}{|c|}{ Delays in preventive care } \\
\hline & $P$ value & $95 \% \mathrm{CI}$ & $P$ value & $95 \% \mathrm{CI}$ & $P$ value & $95 \% \mathrm{CI}$ & $P$ value & $95 \% \mathrm{CI}$ \\
\hline Age (years; 10-year increments) & $<.001$ & $1.12-1.28$ & .25 & $0.95-1.19$ & $<.001$ & $1.15-1.53$ & .18 & $0.96-1.22$ \\
\hline \multicolumn{9}{|l|}{ Gender } \\
\hline Cisgender men & $<.001$ & $0.46-0.78$ & .93 & $0.60-1.59$ & .17 & $0.27-1.20$ & .60 & $0.50-1.46$ \\
\hline Transgender or nonbinary individuals & .36 & $0.80-1.81$ & .75 & $0.56-2.16$ & .48 & $0.55-3.03$ & .39 & $0.29-1.52$ \\
\hline \multicolumn{9}{|l|}{ Race } \\
\hline People of color & .07 & $0.64-1.02$ & .70 & $0.70-1.68$ & .10 & $0.89-2.69$ & .05 & $0.34-0.99$ \\
\hline \multicolumn{9}{|l|}{ Sexual identity } \\
\hline Sexual minority & .01 & $1.04-1.46$ & .28 & $0.63-1.14$ & .31 & $0.82-1.81$ & .26 & $0.61-1.14$ \\
\hline \multicolumn{9}{|l|}{ Education } \\
\hline $\begin{array}{l}\text { Bachelor's degree or some graduate } \\
\text { school }\end{array}$ & .43 & $0.87-1.40$ & .63 & $0.72-1.71$ & .87 & $0.60-1.90$ & .32 & $0.79-2.09$ \\
\hline Graduate or doctorate degree & .02 & $1.03-1.64$ & .85 & $0.69-1.57$ & .58 & $0.69-2.03$ & .07 & $0.96-2.39$ \\
\hline Distance (miles) to nearest hospital & .34 & $0.96-1.13$ & .31 & $0.81-1.07$ & .68 & $0.80-1.16$ & .70 & $0.89-1.19$ \\
\hline $\begin{array}{l}\text { Worry about general health (10-point incre- } \\
\text { ments) }\end{array}$ & .01 & $1.01-1.08$ & .002 & $0.86-0.97$ & .02 & $1.01-1.19$ & .95 & $0.94-1.06$ \\
\hline Worry about COVID (10-point inccrements) & .88 & $0.96-1.05$ & .35 & $0.96-1.12$ & .62 & 0.88-1.09 & .72 & $0.93-1.10$ \\
\hline Intercept & $<.001$ & $0.17-0.44$ & .41 & $0.31-1.62$ & $<.001$ & $0.01-0.12$ & $<.001$ & $0.09-0.53$ \\
\hline
\end{tabular}

${ }^{\mathrm{a}}$ The reference group for all categorical variables are as follows: cisgender woman (gender), White (race), heterosexual (sexual identity), and less than Bachelor's degree (education).

${ }^{b}$ There were 2570 observations for any delays, 907 observations for delays in dental care, 907 observations for delays in diagnostics, and 907 observations for delays in preventive care.

\section{Discussion}

\section{Principal Findings}

In June 2020, Dr Lasic, an interventional cardiologist at Jamaica Hospital Medical Center and Lenox Hill Hospital in New York, made the following prediction: "I think the toll on non-COVID patients will be much greater than COVID deaths" [18]. To our knowledge, ours is the only study that aimed at understanding the toll on patients without COVID-19 by describing rates of multiple types of health care delays as well as characterizing people who were the most affected by these delays during the beginning of the pandemic. In June 2020, under dynamic circumstances, researchers found that $32 \%$ and $12 \%$ of adults deliberately delayed or avoided routine care and emergency care, respectively [19]. Our findings suggest that a not insignificant proportion of the US populace may be experiencing delayed or interrupted care as a result of the pandemic, which may lead to decrements in health over the long term. Across all types of delays, older people, people with higher levels of education, and people who were more worried about their health were more likely to report delays or interruptions in their care. Men and people of color were less likely to report delays or interruptions.

Our findings highlight that dental care appears to be the most impacted (reported by over one-third of participants; 351/921, $38.1 \%$ ). This is unsurprising, given that many dental offices closed at the outset of the pandemic due to concerns of patient and provider safety. However, studies have shown a relationship between dental health and heart disease, between dental health and diabetes, and between dental health and prenatal outcomes [20-22]. This is suggestive of the potential, downstream, deleterious health implications of delayed or interrupted dental care. Dentists are often also on the frontlines of identifying child abuse [23] and intimate partner violence [24], of which both have reportedly increased in incidence during the pandemic [25-27]. Further, a recent study conducted in Qatar has suggested that routine oral care is associated with a reduction in the risk of COVID-19 complications (eg, hospitalization and ventilation) [28]. Several months into the pandemic (July 2020), the American Dental Association released a policy declaring that dentistry was essential care (ie, care that is integral to systemic health) [29]. Of great concern are our findings associated with the frequency of reported delays in preventive and diagnostic care, particularly delays in such care for older adults. The implications of this finding are described in the Introduction section.

The lessons learned from the initial surge of COVID-19 cases can help mitigate potential future disruptions. Mitigation strategies for future disruptions include effective patient prioritization and triage [30-34]. For instance, Medically Necessary Time-Sensitive Prioritization is a scoring system for surgical triage that integrates multiple factors associated with 
the environment, patient risk, and ethics that are intended to be generalizable across hospital settings [35]. Additionally, the Centers for Medicare \& Medicaid Services have released guidelines for the provision of non-COVID-19 care [36-38], However, considerations should also include patient life factors (eg, family support and transportation) as well as systems factors at the hospital (eg, visitation policy), local and state (eg, infection control mandates), or national levels (eg, policies). Using systems thinking perspectives is necessary for addressing complex problems [39]. Cancer care providers have also recommended balancing delays against COVID-19 risk, practicing effective social distancing, and managing the appropriate allocation of resources [32]. Key to reducing delays among patients is the relaying of accessible, clear, and actionable messaging by health care systems about how and when to safely access health care.

More research on health care delays and interruptions during the pandemic is needed. Further investigation is needed into the differences between the care of chronic illness and emergent conditions. For instance, the first pandemic surge resulted in a decline in hospitalization rates and lengths of hospital stay associated with acute cardiovascular conditions as well as other common conditions, such as acute appendicitis, bone fractures, cancer, and live births. Given the evidence on differences based on sex [40], race and ethnicity [41], sexual and gender identity $[42,43]$, and other key factors, we need to investigate sociodemographic differences in delayed or interrupted care. Further, the significant economic effects of the COVID-19 pandemic as well as the high rates of job loss may result in the loss of insurance. Thus, more work is needed to understand how these factors affect health care. The potential impacts on patient-level outcomes such as mental health, quality of life, and pain must also be considered.

\section{Study Limitations}

There are some key limitations that need to be considered. First, this study relied on a convenience sample that is not representative in terms of race, ethnicity, education, age, and gender. Convenience samples are limited in terms of the generalizability of prevalence rates. However, they have the advantage of efficiency, which is critical in a dynamic situation, and can be useful for understanding patterns and relationships associated with a phenomenon of interest. Recent research has shown that internet-based convenience samples correlate with truly random probability samples to a surprising extent. For example, Mullinix et al [44] found a correlation of 0.75 when they conducted 20 experiments that replicated results based on national probability samples on Amazon Mechanical Turk (an internet-based survey platform). More recently, Coppock [45] conducted 15 replication experiments and similarly found that convenience and national probability samples provided similar estimates of treatment and moderator effects. However, despite the limitation of using a convenience sample, our study is unique and critical to documenting experiences at the outset of the pandemic, given that the conditions under which the data were collected are not replicable. In addition, a study conducted over the internet does not reach individuals who do not have access to the internet. However, this is perhaps the only mechanism for capturing data from a fleeting moment in time that is characterized by dynamic and uncertain circumstances.

\section{Conclusions}

The pandemic has amplified people's attention to health disparities and inequities in the United States and has created a need for inclusive and equitable research. The limitations of this study highlight pervasive gaps and challenges associated with conducting such research (and doing so efficiently, given the dynamic nature of the COVID-19 pandemic). There is an urgent need for sharing lessons learned, disseminating effective strategies for reaching more diverse populations (eg, engaging leaders of marginalized communities, understanding and addressing research hesitancy, etc), and encouraging the research community to use and improve upon these strategies in future research. Although the conditions for this study cannot be replicated, the methodological lessons learned can serve as a sort of pilot study for future crises, thereby creating more diverse and inclusive bodies of research that drive health equity forward. Without explicit discussions of research limitations, the research community cannot make progress in collecting data to inform the design of effective programs for addressing health inequities that have existed long before the COVID-19 health crisis. The impact of health care disruptions resulting from the COVID-19 pandemic may be difficult to measure in the short term. However, characterizing these disruptions and improving research methods for such characterizations is critical to informing systemic and equitable planning, mitigation, and recovery strategies for the long term.

\section{Acknowledgments}

The open-access publication fee for this article was supported by the Research Open Access Publishing Fund of the University of Illinois at Chicago.

\section{Conflicts of Interest}

None declared.

\section{References}

1. Flume P, Gray S, Bowman CM, Kerrigan C, Lester M, Virella-Lowell I. Emergency preparedness for the chronically ill. Am J Nurs 2005 Mar;105(3):68-72. [doi: 10.1097/00000446-200503000-00028] [Medline: 15729049]

2. Ford ES, Mokdad AH, Link MW, Garvin WS, McGuire LC, Jiles RB, et al. Chronic disease in health emergencies: in the eye of the hurricane. Prev Chronic Dis 2006 Apr;3(2):A46 [FREE Full text] [Medline: 16539787] 
3. Ryan BJ, Franklin RC, Burkle FM, Aitken P, Smith E, Watt K, et al. Reducing disaster exacerbated non-communicable diseases through public health infrastructure resilience: Perspectives of Australian disaster service providers. PLoS Curr 2016 Dec 21;8:1-26 [FREE Full text] [doi: 10.1371/currents.dis.d142f36b6f5eeca806d95266b20fed1f] [Medline: 28239511]

4. Slama S, Kim HJ, Roglic G, Boulle P, Hering H, Varghese C, et al. Care of non-communicable diseases in emergencies. Lancet 2017 Jan 21;389(10066):326-330. [doi: 10.1016/S0140-6736(16)31404-0] [Medline: 27637675]

5. Papautsky EL, Hamlish T. Patient-reported treatment delays in breast cancer care during the COVID-19 pandemic. Breast Cancer Res Treat 2020 Nov;184(1):249-254 [FREE Full text] [doi: 10.1007/s10549-020-05828-7] [Medline: 32772225]

6. Farley TA, Dalal MA, Mostashari F, Frieden TR. Deaths preventable in the U.S. by improvements in use of clinical preventive services. Am J Prev Med 2010 Jun;38(6):600-609. [doi: 10.1016/j.amepre.2010.02.016] [Medline: 20494236]

7. Maciosek MV, Coffield AB, Flottemesch TJ, Edwards NM, Solberg LI. Greater use of preventive services in U.S. health care could save lives at little or no cost. Health Aff (Millwood) 2010 Sep;29(9):1656-1660. [doi: 10.1377/hlthaff.2008.0701] [Medline: 20820022]

8. McGlynn EA, Asch SM, Adams J, Keesey J, Hicks J, DeCristofaro A, et al. The quality of health care delivered to adults in the United States. N Engl J Med 2003 Jun 26;348(26):2635-2645. [doi: 10.1056/NEJMsa022615] [Medline: 12826639]

9. Niccoli T, Partridge L. Ageing as a risk factor for disease. Curr Biol 2012 Sep 11;22(17):R741-R752 [FREE Full text] [doi: 10.1016/j.cub.2012.07.024] [Medline: 22975005]

10. Werner MT, Carey RM, Albergotti WG, Lukens JN, Brody RM. Impact of the COVID-19 Pandemic on the Management of Head and Neck Malignancies. Otolaryngol Head Neck Surg 2020 Jun;162(6):816-817. [doi: 10.1177/0194599820921413] [Medline: 32312163]

11. Stensland KD, Morgan TM, Moinzadeh A, Lee CT, Briganti A, Catto JWF, et al. Considerations in the triage of urologic surgeries during the COVID-19 pandemic. Eur Urol 2020 Jun;77(6):663-666 [FREE Full text] [doi:

10.1016/j.eururo.2020.03.027] [Medline: 32279903]

12. Reza N, DeFilippis EM, Jessup M. Secondary impact of the COVID-19 pandemic on patients with heart failure. Circ Heart Fail 2020 May;13(5):e007219. [doi: 10.1161/CIRCHEARTFAILURE.120.007219] [Medline: 32352841]

13. Ding YY, Ramakrishna S, Long AH, Phillips CA, Montiel-Esparza R, Diorio CJ, et al. Delayed cancer diagnoses and high mortality in children during the COVID-19 pandemic. Pediatr Blood Cancer 2020 Sep;67(9):e28427 [FREE Full text] [doi: 10.1002/pbc.28427] [Medline: $\underline{32588960]}$

14. Patt D, Gordan L, Diaz M, Okon T, Grady L, Harmison M, et al. Impact of COVID-19 on cancer care: How the pandemic Is delaying cancer diagnosis and treatment for American seniors. JCO Clin Cancer Inform 2020 Nov;4:1059-1071 [FREE Full text] [doi: $10.1200 / C C I .20 .00134]$ [Medline: $\underline{33253013}$ ]

15. Braun V, Clark V. Thematic analysis. In: Cooper H, Camic PM, Long DL, Panter AT, Rindskopf D, Sher KJ, editors. APA Handbook of Research Methods in Psychology: Vol. 2. Research Designs: Quantitative, qualitative, neuropsychological, and biological. Washington, DC, US: American Psychological Association; 2012:57-71.

16. Ryan GW, Bernard HR. Data management and analysis methods. In: Denzin NK, Lincoln YS, editors. Handbook of Qualitative Research, 2nd Edition. Thousand Oaks: Sage Publications; 2000:769-802.

17. The R Project for Statistical Computing. The R Foundation. URL: https://www.r-project.org/ [accessed 2021-05-05]

18. Rosenbaum L. The untold toll - The pandemic's effects on patients without Covid-19. N Engl J Med 2020 Jun 11;382(24):2368-2371. [doi: 10.1056/NEJMms2009984] [Medline: 32302076]

19. Czeisler ME, Marynak K, Clarke KEN, Salah Z, Shakya I, Thierry JM, et al. Delay or avoidance of medical care because of COVID-19-related concerns - United States, June 2020. MMWR Morb Mortal Wkly Rep 2020 Sep 11;69(36):1250-1257 [FREE Full text] [doi: 10.15585/mmwr.mm6936a4] [Medline: $\underline{\text { 32915166] }}$

20. Khader YS, Ta'ani Q. Periodontal diseases and the risk of preterm birth and low birth weight: a meta-analysis. J Periodontol 2005 Feb;76(2):161-165. [doi: 10.1902/jop.2005.76.2.161] [Medline: 15974837]

21. Sanz M, Ceriello A, Buysschaert M, Chapple I, Demmer RT, Graziani F, et al. Scientific evidence on the links between periodontal diseases and diabetes: Consensus report and guidelines of the joint workshop on periodontal diseases and diabetes by the International diabetes Federation and the European Federation of Periodontology. Diabetes Res Clin Pract 2018 Mar;137:231-241. [doi: 10.1016/j.diabres.2017.12.001] [Medline: 29208508]

22. Yu YH, Chasman DI, Buring JE, Rose L, Ridker PM. Cardiovascular risks associated with incident and prevalent periodontal disease. J Clin Periodontol 2015 Jan;42(1):21-28 [FREE Full text] [doi: 10.1111/jcpe.12335] [Medline: 25385537]

23. Smitt HS, de Leeuw J, de Vries T. Association between severe dental caries and child abuse and neglect. J Oral Maxillofac Surg 2017 Nov;75(11):2304-2306. [doi: 10.1016/j.joms.2017.05.004] [Medline: 28586637]

24. Lea SJ, Quinn B, Reynolds PA. The role and education of dental care professionals in identifying domestic violence: Report of an audience participation exercise and round table discussion. Technology, Knowledge and Learning 2016 Dec 2;22:219-226 [FREE Full text] [doi: 10.1007/s10758-016-9293-9]

25. Bettinger-Lopez C, Bro A. A double pandemic: Domestic violence in the age of COVID-19. Council on Foreign Regulations. 2020 May 13. URL: https://www.cfr.org/in-brief/double-pandemic-domestic-violence-age-covid-19 [accessed 2021-05-06]

26. Brown SM, Doom JR, Lechuga-Peña S, Watamura SE, Koppels T. Stress and parenting during the global COVID-19 pandemic. Child Abuse Negl 2020 Dec;110(Pt 2):104699 [FREE Full text] [doi: 10.1016/j.chiabu.2020.104699] [Medline: 32859394] 
27. Velonis A, McGown M. When home does not offer shelter: partner violence in the time of pandemics. University of Illinois Chicago. 2020 Apr 04. URL: https://publichealth.uic.edu/news-stories/ when-home-does-not-offer-shelter-partner-violence-in-the-time-of-pandemics/ [accessed 2021-05-06]

28. Marouf N, Cai W, Said KN, Daas H, Diab H, Chinta V, et al. Association between periodontitis and severity of COVID-19 infection: A case-control study. J Clin Periodontol 2021 Apr;48(4):483-491 [FREE Full text] [doi: 10.1111/jcpe.13435] [Medline: 33527378 ]

29. Current policies. American Dental Association. URL: https://www.ada.org/en/advocacy/ current-policies\#publichealthemergencies [accessed 2020-09-16]

30. Brody RM, Albergotti WG, Shimunov D, Nicolli E, Patel UA, Harris BN, et al. Changes in head and neck oncologic practice during the COVID-19 pandemic. Head Neck 2020 Jul;42(7):1448-1453 [FREE Full text] [doi: 10.1002/hed.26233] [Medline: $\underline{32357380}$ ]

31. Hanna TP, Evans GA, Booth CM. Cancer, COVID-19 and the precautionary principle: prioritizing treatment during a global pandemic. Nat Rev Clin Oncol 2020 May;17(5):268-270 [FREE Full text] [doi: 10.1038/s41571-020-0362-6] [Medline: 32242095]

32. Kutikov A, Weinberg DS, Edelman MJ, Horwitz EM, Uzzo RG, Fisher RI. A war on two fronts: Cancer care in the time of COVID-19. Ann Intern Med 2020 Jun 02;172(11):756-758 [FREE Full text] [doi: 10.7326/M20-1133] [Medline: $\underline{32219410]}$

33. Nagar H, Formenti SC. Cancer and COVID-19 - potentially deleterious effects of delaying radiotherapy. Nat Rev Clin Oncol 2020 Jun;17(6):332-334 [FREE Full text] [doi: 10.1038/s41571-020-0375-1] [Medline: 32341524]

34. O'Leary MP, Choong KC, Thornblade LW, Fakih MG, Fong Y, Kaiser AM. Management considerations for the surgical treatment of colorectal cancer during the global Covid-19 pandemic. Ann Surg 2020 Aug;272(2):e98-e105 [FREE Full text] [doi: 10.1097/SLA.0000000000004029] [Medline: 32675510]

35. Prachand VN, Milner R, Angelos P, Posner MC, Fung JJ, Agrawal N, et al. Medically necessary, time-sensitive procedures: Scoring system to ethically and efficiently manage resource scarcity and provider risk during the COVID-19 pandemic. J Am Coll Surg 2020 Aug;231(2):281-288 [FREE Full text] [doi: 10.1016/j.jamcollsurg.2020.04.011] [Medline: 32278725]

36. Helping private practices navigate non-essential care during COVID-19. American Medical Association. URL: https://www. ama-assn.org/delivering-care/public-health/helping-private-practices-navigate-non-essential-care-during-covid-19 [accessed 2020-09-18]

37. Healthcare facilities: Managing operations during the COVID-19 pandemic. Centers for Disease Control and Prevention. URL: https://www.cdc.gov/coronavirus/2019-ncov/hcp/guidance-hcf.html [accessed 2020-09-18]

38. Coronavirus (COVID-19) partner resources. Centers for Medicare \& Medicaid Services. URL: https://www.cms.gov/ outreach-education/partner-resources/coronavirus-covid-19-partner-toolkit [accessed 2020-09-18]

39. Holden RJ, Carayon P, Gurses AP, Hoonakker P, Hundt AS, Ozok AA, et al. SEIPS 2.0: a human factors framework for studying and improving the work of healthcare professionals and patients. Ergonomics 2013;56(11):1669-1686 [FREE Full text] [doi: 10.1080/00140139.2013.838643] [Medline: 24088063]

40. Veldhuis CB, Maki P, Molina K. Psychological and neighborhood factors associated with urban women's preventive care use. J Behav Med 2020 Jun;43(3):346-364 [FREE Full text] [doi: 10.1007/s10865-019-00122-4] [Medline: 31865485]

41. Phillips KA, Mayer ML, Aday LA. Barriers to care among racial/ethnic groups under managed care. Health Aff (Millwood) 2000;19(4):65-75. [doi: 10.1377/hlthaff.19.4.65] [Medline: 10916961]

42. Hsieh N, Ruther M. Despite increased insurance coverage, nonwhite sexual minorities still experience disparities in access to care. Health Aff (Millwood) 2017 Oct 01;36(10):1786-1794. [doi: 10.1377/hlthaff.2017.0455] [Medline: 28971924]

43. Progovac AM, Lê Cook B, Mullin BO, McDowell A, Sanchez R MJ, Wang Y, et al. Identifying gender minority patients' health and health care needs in administrative claims data. Health Aff (Millwood) 2018 Mar;37(3):413-420 [FREE Full text] [doi: 10.1377/hlthaff.2017.1295] [Medline: 29505378]

44. Mullinix KJ, Leeper TJ, Druckman JN, Freese J. The generalizability of survey experiments. Journal of Experimental Political Science 2016 Jan 12;2(2):109-138. [doi: 10.1017/xps.2015.19]

45. Coppock A. Generalizing from survey experiments conducted on Mechanical Turk: A replication approach. Political Science and Research Methods 2018 Mar 27;7(3):613-628 [FREE Full text] [doi: 10.1017/psrm.2018.10] 
Edited by R Kukafka, C Basch; submitted 02.11.20; peer-reviewed by M Koo, J Ziegenfuss, M Callegaro; comments to author 14.01.21; revised version received 16.03.21; accepted 20.04.21; published 19.05.21

Please cite as:

Papautsky EL, Rice DR, Ghoneima H, McKowen ALW, Anderson N, Wootton AR, Veldhuis C

Characterizing Health Care Delays and Interruptions in the United States During the COVID-19 Pandemic: Internet-Based,

Cross-sectional Survey Study

J Med Internet Res 2021;23(5):e25446

URL: https://www.jmir.org/2021/5/e25446

doi: $\frac{10.2196 / 25446}{D: 33886489}$

PMID: $\underline{38886489}$

CElizabeth Lerner Papautsky, Dylan R Rice, Hana Ghoneima, Anna Laura W McKowen, Nicholas Anderson, Angie R Wootton, Cindy Veldhuis. Originally published in the Journal of Medical Internet Research (https://www.jmir.org), 19.05.2021. This is an open-access article distributed under the terms of the Creative Commons Attribution License (https://creativecommons.org/licenses/by/4.0/), which permits unrestricted use, distribution, and reproduction in any medium, provided the original work, first published in the Journal of Medical Internet Research, is properly cited. The complete bibliographic information, a link to the original publication on https://www.jmir.org/, as well as this copyright and license information must be included. 